\title{
Obstacles to implementing total quality management in Saudi Arabia marketing tourism Ser- vices
}

\author{
Nabil Mohammed AL-Hazmi ${ }^{a, b^{*}}$ and Tarek Tawfik Yousef Alkhateeb ${ }^{c}$
}

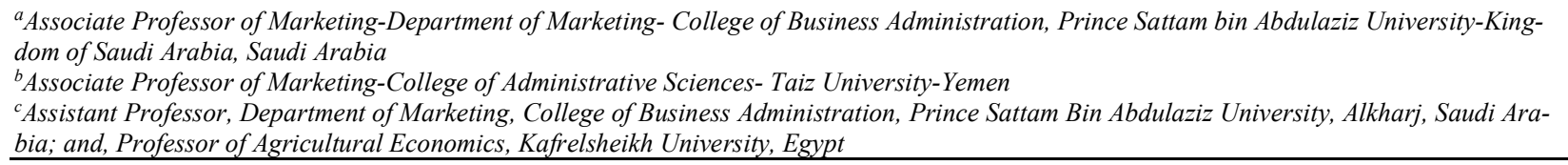

\section{H R O N I C L E}

\section{Article history:}

Received: August 192019

Received in revised format: August 192019

Accepted: September 27, 2019

Available online:

September 27, 2019

Keywords:

Total Quality Management

Marketing

Tourism

\section{A B S T R A C T}

The purpose of this paper was to identify different obstacles preventing the application and activating the overall quality management in marketing tourism services in Saudi Arabia. The study found a number of key findings on the constraints of applying overall quality management in marketing tourism services in Saudi Arabia. The study recommended the need to adopt an integrated system of comprehensive quality management in hotel organizations in Al-Kharj governorate in order to ensure the implementation of sound and correct marketing programs for these organizations by removing the obstacles, which stand in the way of the application of managing the overall quality of these organizations.

\section{Introduction}

The tourism sector in Saudi Arabia has become one of the national sectors, which is launching towards development horizons. This is due to the State's keen patronage to support this sector through ambitious plans and huge potentials to ensure the continuity of supporting the infrastructure of this sector and providing facilities for attracting and marketing investors. It has become an economic resource that contributes to the diversification of national income sources as this is a strategic objective for the vision of the Kingdom of 2030. The concept of tourism marketing refers to the administrative and technical activity carried out by the tourism organizations and tourist facilities within and outside the country to identify and influence the upcoming tourist markets in order to develop the tourism movement to achieve the maximum amount of tourism revenues. It is also a process aimed at understanding the tourist and its behavior and at planning and monitoring relations between various sectors related to tourism for the suitability of its products and services to support the wishes of the tourism industry. Tourism marketing has become one of the main factors on which the Kingdom relies on increasing its share of the domestic and international tourism movement (Bathath, 2017). The current markets are characterized by fierce competition between tourist establishments, in order to satisfy the needs and requirements of consumers and to ensure that these organizations enjoy the competitive advantages that allow them to retain. Most companies have maintained the desire to survive and grow and to adopt a new philosophy based on providing higher value to the target consumer. It should be noted that the term total quality refers to the adoption of a comprehensive management policy followed by the institution which involves a set of steps and procedures to ensure access to a certain level of productivity which satisfies the companies and the clients. Therefore, the organizations in general including tourism organizations in particular are adopting the concept of comprehensive quality and

\footnotetext{
* Corresponding author
}

E-mail address: alhazmi1976@gmail.com (N. M. AL-Hazmi) 
its application and explanation to all levels of management and employees of the company with the development of an action plan including procedures and methods to be walked and then the process of evaluation, supervision and follow-up to achieve the concept of total quality. It is understood that the implementation of this concept is in line with the trends and plans of development in the Kingdom of Saudi Arabia where attention is directed to the tourism sector as one of the promising sectors which contributes to diversify of the sources of national income of the Kingdom. But, the application of total quality management (TQM) in the tourism sector and the marketing of hotel services in particular faces a number of difficulties and challenges. These obstacles vary between social, legal, administrative, political and others, all of which serve as a barrier to the proper application of the concept of TQM and delay the development of tourism in particular economic development (Abdulsttar, 2013; Alathathi, 2012).

\subsection{Research Problem}

In light of the Kingdom's tendency to diversify sources of income, the importance of tourism sector is a reliable source of diversification in line with the vision of the Kingdom 2030. Therefore, tourism organizations aspire to implement TQM as a strategic approach. However, the application of this system in the marketing of tourism services in the hotel sector in the Kingdom including Al-Kharj is directed by some of the obstacles or difficulties which may prevent the activation of this sector for its pioneering role to support the Saudi economic structure and may become clear to solve the problems.

\subsection{Research Objectives}

The present research aims to achieve a number of objectives as follows:

1. It identifies the main obstacles which prevent the implementation of TQM system in the tourism sector.

2. It develops the mechanisms or solutions to address these difficulties and to do the role of this tourism sector in diversifying the Saudi economy under the vision of the Kingdom 2030.

\subsection{Research Methodology}

The research was based on quantitative descriptive statistical methodology for analyzing the statistical data collected from primary sources including geographical area to cover Al-Kharj governorate. The study variables are based on a number of quantitative and qualitative indicators of tourism and related aspects. The size of the sample was determined using the sample size calculator, available at http://www.macorr.com/ss calculator.htm with a confidence level of $95 \%$ based on the official statistics of tourist establishments in Al-Kharj governorate. The selection of a random sample of (80) single staff is included workers in the hotel sector where the rate of retrieval was $100 \%$ and all data was completed for valid statistical analysis. With respect to data collection tools, the questionnaire, personal interview, group discussions and case study were varied to support the compilation of quantitative and qualitative data on the variables of the study.

\subsection{The hypothesis of the study}

There are a number of major constraints for the application of TQM in the marketing of hotel services in the Kingdom of Saudi Arabia (Al-Kharj governorate).

\subsection{The Study Tool}

In order to achieve the objectives of the study, the researchers built the study tool of the questionnaire which consisted of two main parts. First part contains the personal data of the research sample members including variables (gender, age, scientific qualification, experience and occupation). Second part contained 55 questions that varied between seven variables including the most important obstacles facing the application of TQM in the tourism sector in Al-Kharj Governorate. For the formulation of the questionnaire, the Likert scale was adopted in its five grades (very agree- agree- nil- not agree- not at all). These answers were given as grading $(1,2,3,4,5)$.

Table 1

\begin{tabular}{llll}
\multicolumn{2}{l}{ Parts of Questioner } & & \\
\hline $\mathrm{N}$. & Obstacles Types & Number of Questions & Percentage $100 \%$ \\
\hline 1 & Administrative Obstacles & 8 & 18.810 \\
2 & Organizational Obstacles & 7 & 20.000 \\
3 & Leadership Obstacles & 5 & 14.550 \\
4 & Competitive Obstacles & 6 & 16.360 \\
5 & Legislation Obstacles & 6 & 18.180 \\
6 & Culture and Social Obstacles & 7 & 16.360 \\
7 & Technological Obstacles & 6 & 16.360 \\
\hline Total & & 45 & 100 \\
\hline
\end{tabular}

\subsection{Test Reliability and Stability Study Tool}

In order to verify the validity of the study tool, the method of honesty was used by presenting the tool to a group of experts who are interested in the research subject and have experience and know-how in the field of business management, marketing 
and TQM in a number of public universities in the Kingdom of Saudi Arabia. The universities of Prince Sattam bin Abdul Aziz, King Khalid bin Abdulaziz University and King Faisal bin Abdul Aziz University are utilized in order to arbitrate the questionnaire in terms of clarity of words and their belonging, language formulation and adequacy of vocabulary for each item. Based on the opinions of the arbitrators, different opinions of the arbitrators were adopted until they settled on their final status, and began to distribute them through a pre-test group in order to conduct a tribal experiment or to select a sample of the study community to be tested. In order to test the stability of the study instrument and to test its internal validity, the Cronbach Alpha test was used to measure the internal consistency coefficient of the scale as a whole. The results indicate a stable degree of response in the sample. The standard Cronbach Alpha (86.1\%) for the scale as a whole was high and acceptable for reliance.

Table 2

Internal consistency coefficient (coefficient of stability - A Kronbach).

\begin{tabular}{lll}
\hline N. & Variables & Coefficients of Cronbach's Alpha \\
\hline 1 & Administrative Obstacles & 0.881 \\
2 & Organizational Obstacles & 0.842 \\
3 & Leadership Obstacles & 0.856 \\
4 & Competitive Obstacles & 0.867 \\
5 & Legislation Obstacles & 0.874 \\
6 & Culture and Social Obstacles & 0.851 \\
7 & Technological Obstacles & 0.872 \\
\hline Total & & 0.861 \\
\hline
\end{tabular}

\subsection{Study Model}

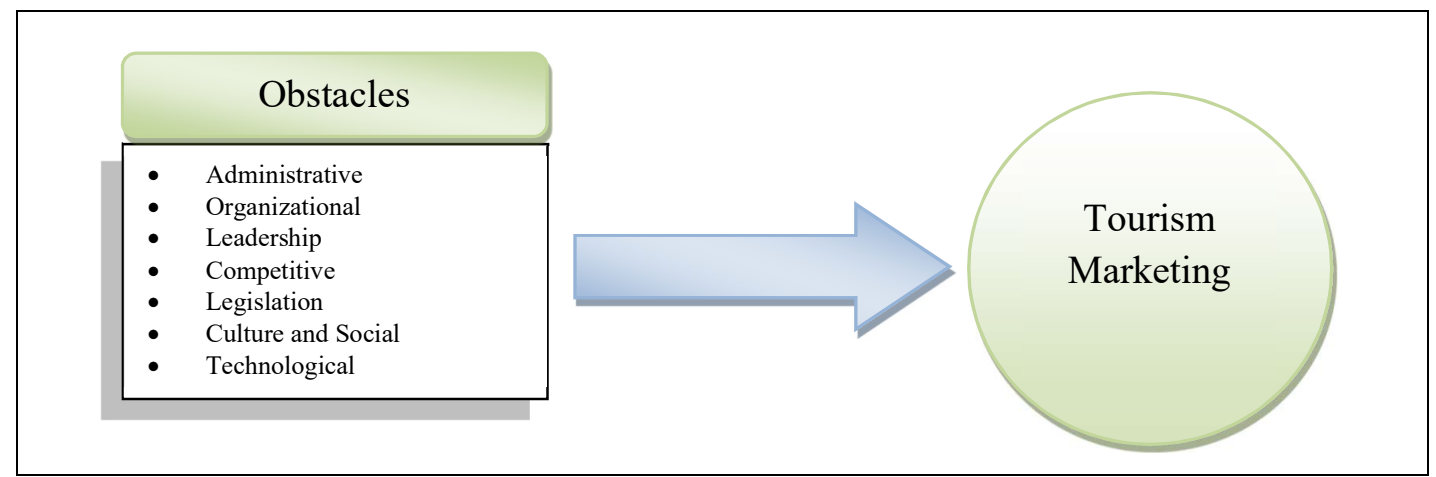

* Prepared by researchers.

\section{Literature Review}

Some researchers found the existence of a range of obstacles that prevent the application of TQM properly managed, and these constraints varied between organizational, administrative, cognitive, financial, social, cultural and others (Alathathi, 2012; Aldaibat, 2018; Alhazmi, 2017). Many studies recommended the necessity to implement TQM in the hotel sector in Jordan due to the importance of this in improving the quality of services provided and raised the level of customer satisfaction. Alhazmi (2017) came to diagnose the reality of applying TQM in Al-Kharj and determined its importance for the success of the tourism sector to achieve the Customers' Satisfaction. Alsosi (2017) concluded that there is no interest in the application of TQM in construction companies as well as the existence of organizational and cognitive obstacles that prevent the proper application of TQM along with the lack of shortage in the implementation of TQM. Communication between the senior management and executive management of the institution was an important factor for the success of TQM implementation. Alhouri (2012) concluded that there is a need for a set of prerequisites and requirements before implementing TQM in the hotel sector. These requirements varied between financial, organizational, knowledge and cultural. The absence of such requirements may impede the application of TQM in the hotel sector in Algeria. Rady (2016) reached a set of organizational and administrative obstacles that prevent the application of TQM in institutions of higher education in the Gaza governorate in Palestine. Alkomaim (2015) concluded to the importance of applying TQM in Yemeni universities, but there is a number of determinants that prevent the application of this concept well. These determinants are characterized by financial, cultural, organizational and cultural determinants. Banoula (2014) aimed to measure the degree of application of marketing by relations in the tourism sector, especially at the level of tourism agencies in Algeria. Mahmood and Ahmed (2014) concluded on the importance of applying TQM and the need to create an organizational and knowledge environment in the organizations in order to ensure an excellent and proper application of the principles of TQM. Alrefai and Alnajdawi (2012) aimed to study the potential and constraints of the application of TQM from the point of view of the employees. The study found that, there were a number of obstacles such as organizational and cognitive obstacles that prevent the application of TQM principles in the administration of education in Taif. Alhouri (2012) stated that the success of the implementation of the principles of TQM 
necessarily depends on the satisfaction of the senior management first and its commitment to support the implementation of this approach. Alathathi (2012) reached a range of cognitive and financial constraints related to the effectiveness of communication channels, which could influence on the correct application of TQM in the institutions of higher education in the Kingdom. Al-Azzawi and Hawamdeh (2010) recommended the need to pay attention to various facilities required for hotel guests and keep pace with the latest developments in hotel service technology in order to raise the overall quality of hotel services. Bazazo (2010) studied on a sample of five-star hotels and reached a number of important results. They reported that the employees of five-star hotels understand the importance of applying the principles of TQM. As indicated by the study results, also there were significant differences in the perception of employees in five-stars hotels to the importance of applying the principles of total quality management. The study also developed a number of recommendations, including the need for continued support of senior management and commitment by applying the principles of TQM with activation of participation and teamwork and consolidation in the organizational culture element. Boubacar (2009) aimed to highlight the nature of the relationship between internal marketing and quality of service in the hotel industry. Ruqaya and Aziz (2017) presented a comprehensive study on requirements for TQM implementation as an approach for developing competitiveness of tourism service in Algeria.

\section{Research results and discussion}

By studying and reviewing the results of previous studies related to the subject of the study and through the experience of researchers, the current research investigates the level of marketing in a number of hotels in Al-Kharj governorate. Thus, the study is recommended the need for further studies dealing with the constraints of applying comprehensive quality management system in marketing hotel services in Al-Kharj city and fill the possible gap.

\subsection{The characteristics of the research sample}

Fig. 2 demonstrates personal characteristics of the participants in this survey.

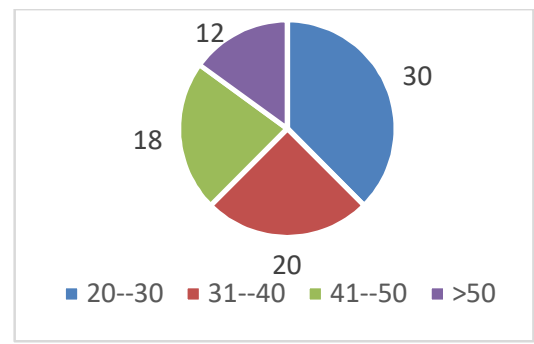

Age

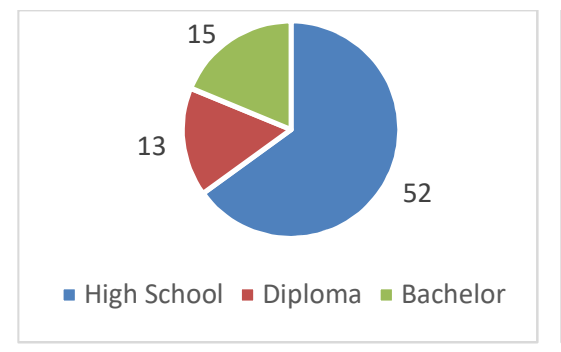

Educational background

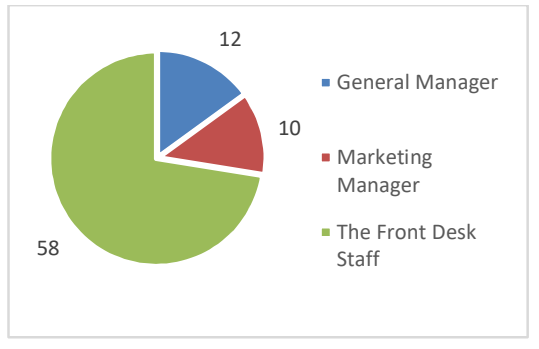

Job title

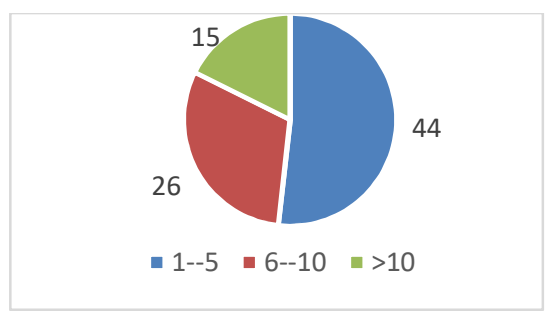

Years of job experience

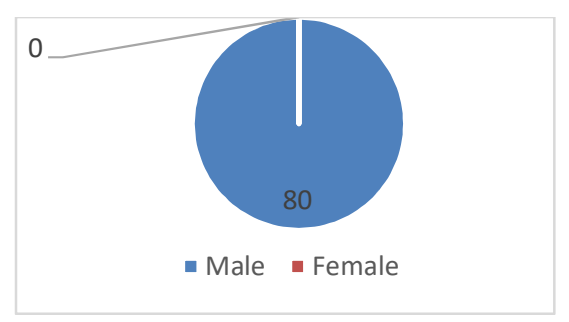

Gender

Fig. 2. Personal characteristics of the participants

By reviewing the characteristics of the research sample community and as stated in Fig. 2, all people participated in our survey were male. About $63 \%$ of the participants in our survey were less than 40 years of age. Most of the participants hold only a high school degree and working as front desk staff. Nearly half of the participants had less than 5 years of job experience.

3.2 The results of the analysis of the main obstacles facing the application of overall quality management in marketing tourism services in Saudi Arabia (Al-Kharj Governorate).

By examining and reviewing the main obstacles facing the application of overall quality management in marketing tourism services in Al-Kharj governorate from Table 3, it is clear that all experimental averages have ranged around the value (3). Despite the convergence between the averages, it is noted that there is a difference between them in terms of the degree of approval where the average total quality was 4.023 and with a standard deviation of 4.103 and the regulatory constraints were the first order with an average value of about 4.301 and a standard deviation also estimated at about 4.441 . 
Table 3

Key obstacles to applying overall quality management in marketing tourism services in Al-Kharj province.

\begin{tabular}{|c|c|c|c|c|c|c|}
\hline \multirow[t]{2}{*}{ N. } & \multirow[t]{2}{*}{ Obstacles } & \multirow[t]{2}{*}{ Mean } & \multirow[t]{2}{*}{ Sd. Devotion } & \multicolumn{3}{|c|}{ Test Result } \\
\hline & & & & $\mathrm{t}$ (value) & Sig. & Result \\
\hline 1 & Administrative Obstacles & 4.292 & 4.421 & 75.582 & $0.000^{*}$ & Sig \\
\hline 2 & Organizational Obstacles & 4.301 & 4.441 & 76.131 & $0.000^{*}$ & Sig \\
\hline 3 & Leadership Obstacles & 3.998 & 4.029 & 74.235 & $0.000^{*}$ & Sig \\
\hline 4 & Competitive Obstacles & 4.001 & 4.321 & 74.021 & $0.000^{*}$ & Sig \\
\hline 5 & Legislation Obstacles & 3.678 & 4.034 & 72.975 & $0.000^{*}$ & Sig \\
\hline 6 & Culture and Social Obstacles & 3.671 & 4.001 & 72.964 & $0.000^{*}$ & Sig \\
\hline 7 & Technological Obstacles & 3.451 & 4.000 & 71.998 & $0.000^{*}$ & Sig \\
\hline To & & 4.023 & 4.103 & 74.140 & $0.000 *$ & Sig \\
\hline
\end{tabular}

* Significance in the level of 0.05

3.3 Statistical analysis of administrative obstacles facing the application overall quality management in marketing tourism services in Al-Kharj province

Notes that according to Table 3, for the administrative constraints facing marketing tourism services in Saudi Arabia (Al-Kharj governorate), the average arithmetic was 4.29 with a standard deviation of about 4.42 and of t-value was about 75.58. It was the highest value of the average in the item of paragraph (6) where it reached 4.23 and a standard deviation 0.63 , and the value ( $\mathrm{t}$ ) of 445 . It indicates poor coordination cooperation between different departments and departments within the hotel organizations. The lowest value of the average arithmetic in the axis of administrative constraints was for paragraph 3, where the average was 3.210 with a standard deviation of 0.92 and the t-value of 33.13 and this was due to the many regulations governing administrative work. In the hotel sector, this hinders the application process comprehensive quality management while marketing hotel programs and activities in Table 4.

\section{Table 4}

Statistical analysis of administrative constraints facing the application of overall quality management in marketing tourism services in Al-Kharj province

\begin{tabular}{|c|c|c|c|c|c|c|c|c|}
\hline \multirow[t]{2}{*}{ Group } & \multirow[t]{2}{*}{ N. } & \multirow[t]{2}{*}{ Obstacles } & \multirow[t]{2}{*}{ Ranks } & \multirow[t]{2}{*}{ Mean } & \multirow[t]{2}{*}{ Sd. Devotion } & \multicolumn{3}{|c|}{ Test Result } \\
\hline & & & & & & $\mathrm{t}$ (value) & Sig. & Result \\
\hline \multirow[t]{8}{*}{ Administrative Obstacles } & 1 & $\mathrm{X} 1$ & 4 & 4.292 & 0.631 & 54.131 & $0.000^{*}$ & Sig \\
\hline & 2 & $\mathrm{X} 2$ & 6 & 4.301 & 0.993 & 34.342 & $0.000^{*}$ & Sig \\
\hline & 3 & $\mathrm{X} 3$ & 8 & 3.998 & 0.918 & 33.123 & $0.000^{*}$ & Sig \\
\hline & 4 & X4 & 3 & 4.001 & 0.625 & 54.231 & $0.000 *$ & Sig \\
\hline & 5 & X5 & 7 & 3.678 & 0.976 & 34.332 & $0.000^{*}$ & Sig \\
\hline & 6 & X6 & 1 & 3.671 & 0.629 & 54.453 & $0.000^{*}$ & Sig \\
\hline & 7 & $\mathrm{X} 7$ & 5 & 3.451 & 0.601 & 53.187 & $0.000 *$ & Sig \\
\hline & 8 & $\mathrm{X} 8$ & 2 & 4.292 & 0.623 & 54.449 & $0.000^{*}$ & Sig \\
\hline \multicolumn{3}{|c|}{ General Average of Administrative Aspects } & \multicolumn{2}{|c|}{4.292} & 4.421 & 75.582 & $0.000^{*}$ & Sig \\
\hline
\end{tabular}

* Significance in the level of 0.05

3.4 Statistical analysis of regulatory obstacles facing application overall quality management in marketing tourism services in Al-Kharj governorate:

Based on the results of Table 4 for regulatory constraints, the overall average of the axis as a whole was approximately (4.30), the standard deviation of about (4.44) and the t-value was about (76.13). The highest average value of paragraph (7) was (4.29), the average deviation was 0.66 and the t-value was about 53.99. It indicates a weakness of staff participation in the process of formulating strategic objectives regarding the overall quality management in marketing tourism services. The lowest value for the average share of paragraph (1) was 3.23 with a standard deviation of 0.92 and the tvalue was about 33.14. It indicates a weakness in cooperation and coordination between the departments of hotel organizations in Al-Kharj governorate.

Table 5

Statistical analysis of regulatory constraints facing the application of overall quality management in marketing tourism services in Al-Kharj province

\begin{tabular}{|c|c|c|c|c|c|c|c|c|}
\hline \multirow[t]{2}{*}{ Group } & \multirow[t]{2}{*}{ N. } & \multirow[t]{2}{*}{ Obstacles } & \multirow[t]{2}{*}{ Ranks } & \multirow[t]{2}{*}{ Mean } & \multirow[t]{2}{*}{ Sd. Devotion } & \multicolumn{3}{|c|}{ Test Result } \\
\hline & & & & & & $\mathrm{t}$ (value) & Sig. & Result \\
\hline \multirow[t]{7}{*}{ Organizational Obstacles } & 1 & X9 & 7 & 3.112 & 0.920 & 33.143 & $0.000 *$ & Sig \\
\hline & 2 & $\mathrm{X} 10$ & 4 & 4.123 & 0.632 & 53.144 & $0.000 *$ & Sig \\
\hline & 3 & $\mathrm{X} 11$ & 2 & 4.128 & 0.634 & 53.154 & $0.000^{*}$ & Sig \\
\hline & 4 & $\mathrm{X} 12$ & 5 & 3.952 & 0.911 & 34.987 & $0.000 *$ & Sig \\
\hline & 5 & $\mathrm{X} 13$ & 6 & 3.286 & 0.898 & 34.121 & $0.000^{*}$ & Sig \\
\hline & 6 & $\mathrm{X} 14$ & 3 & 4.125 & 0.635 & 53.231 & $0.000 *$ & Sig \\
\hline & 7 & $\mathrm{X} 15$ & 1 & 4.287 & 0.653 & 53.987 & $0.000 *$ & Sig \\
\hline \multicolumn{3}{|c|}{ General Average of Organizational Aspects } & \multicolumn{2}{|c|}{4.301} & 4.441 & 76.131 & $0.000^{*}$ & Sig \\
\hline
\end{tabular}

\footnotetext{
* Significance in the level of 0.05
} 
3.5 Statistical analysis of leadership constraints facing the application of overall quality management in marketing tourism services in Al-Kharj province:

The results of the statistical analysis in Table 6 for leadership constraints show that the overall average of all paragraphs as a whole was about (3.99) with a standard deviation estimated at about (4.03) and the t-value was about (74.24). It was the highest average value in the terms of paragraph (5) where the value of the arithmetic average was about (4.29) with a standard deviation estimated at (0.65) and t-value of 54.36. Perhaps due to the uniqueness of issuing orders and the lack of sufficient initiative by some individuals, it affects the trend towards the application of comprehensive quality management in marketing hotel services.

Table 6

Statistical analysis of leadership constraints facing the application of overall quality management in marketing tourism services in Al-Kharj province

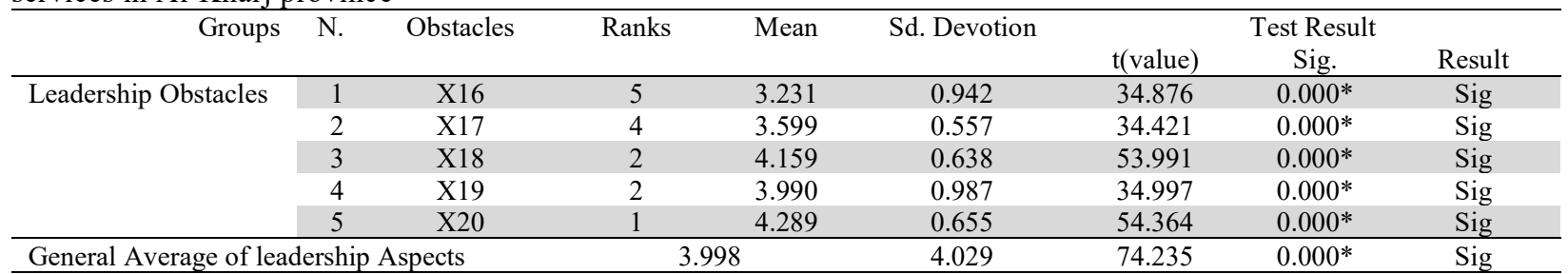

* Significance in the level of 0.05

3.6 Statistical analysis of the competitive constraints facing the application overall quality management in marketing tourism services in Al-Kharj province

By studying and analyzing the competitive constraints faced by tourism organizations in their management of overall quality, Table 7 shows that their overall average was (4.00) with a standard deviation estimated of (4.32) and with the tvalue of 74.02 .

Table 7

Statistical analysis of the competitive constraints facing the application overall quality management in marketing tourism services in Al-Kharj province

\begin{tabular}{|c|c|c|c|c|c|c|c|c|}
\hline \multirow[t]{2}{*}{ Groups } & \multirow[t]{2}{*}{ N. } & \multirow[t]{2}{*}{ Obstacles } & \multirow[t]{2}{*}{ Ranks } & \multirow[t]{2}{*}{ Mean } & \multirow[t]{2}{*}{ Sd. Devotion } & \multicolumn{3}{|c|}{ Test Result } \\
\hline & & & & & & $\mathrm{t}$ (value) & Sig. & Result \\
\hline \multirow[t]{6}{*}{ Competitive Obstacles } & 1 & $\mathrm{X} 21$ & 8 & 4.001 & 0.675 & 53.001 & $0.000^{*}$ & Sig \\
\hline & 2 & $\mathrm{X} 22$ & 2 & 4.237 & 0.686 & 54.112 & $0.000 *$ & Sig \\
\hline & 3 & $\mathrm{X} 23$ & 2 & 4.891 & 0.633 & 54.988 & $0.000 *$ & Sig \\
\hline & 4 & $\mathrm{X} 24$ & 6 & 3.965 & 0.876 & 34.798 & $0.000^{*}$ & Sig \\
\hline & 5 & $\mathrm{X} 25$ & 5 & 3.991 & 0.899 & 34.998 & $0.000^{*}$ & Sig \\
\hline & 6 & $\mathrm{X} 26$ & 23 & 4.011 & 0.679 & 53.201 & $0.000 *$ & Sig \\
\hline \multicolumn{3}{|c|}{ General Average of Competitive Aspects } & \multicolumn{2}{|c|}{4.001} & 4.321 & 74.021 & $0.000^{*}$ & Sig \\
\hline
\end{tabular}

* Significance in the level of 0.05

3.7 Statistical analysis of legislative constraints facing the application of overall quality management in marketing Tourism services in Al-Kharj province

By examining and analyzing the specific factors of legislative constraints facing the application of overall quality management in marketing tourism services in Al-Kharj governorate, it is cleared from Table 8 that the average of total was about (3.68) with a standard deviation of about (4.03) as t-value was about (72.97). The highest value scoring for the average share of the No. (5) was (4.02) with a standard deviation at about (0.64) and with the t-value of (53.98). It indicates a weakness in the lack of legal training among the staff of hotel organizations in al-Kharj governorate. While, the minimum average value was about (3.01) and the standard deviation was estimated at about (0.90) for the term (3) which shows a weak control of hotel and tourism activity in the province.

Table 8

Statistical analysis of legislative constraints facing the application of overall quality management in marketing tourism services in Al-Kharj province

\begin{tabular}{|c|c|c|c|c|c|c|c|c|}
\hline \multirow[t]{2}{*}{ Groups } & \multirow[t]{2}{*}{ N. } & \multirow[t]{2}{*}{ Obstacles } & \multirow[t]{2}{*}{ Ranks } & \multirow[t]{2}{*}{ Mean } & \multirow[t]{2}{*}{ Sd. Devotion } & \multicolumn{3}{|c|}{ Test Result } \\
\hline & & & & & & $\mathrm{t}$ (value) & Sig. & Result \\
\hline \multirow[t]{6}{*}{ Legislation Obstacles } & 1 & $\mathrm{X} 37$ & 2 & 4.000 . & 0.621 & 53.001 & $0.000^{*}$ & Sig \\
\hline & 2 & $\mathrm{X} 28$ & 5 & 3.215 & 0.941 & 34.234 & $0.000^{*}$ & Sig \\
\hline & 3 & X29 & 6 & 3.012 & 0.901 & 33.104 & $0.000^{*}$ & Sig \\
\hline & 4 & $\mathrm{X} 30$ & 3 & 3.991 & 0.821 & 34.996 & $0.000^{*}$ & Sig \\
\hline & 5 & X31 & 1 & 4.019 & 0.643 & 53.976 & $0.000^{*}$ & Sig \\
\hline & 6 & $\mathrm{X} 32$ & 4 & 3.532 & 0.947 & 34.323 & $0.000^{*}$ & Sig \\
\hline \multicolumn{3}{|c|}{ General Average of Legislation Aspects } & 3.678 & & 4.034 & 72.975 & $0.000^{*}$ & Sig \\
\hline
\end{tabular}

* Significance in the level of 0.05 
3.7 Statistical analysis of cultural and social obstacles facing the application of overall quality management in marketing tourism services in Al-Kharj province:

By studying and analyzing the specific factors of cultural and social constraints, it is cleared from Table 9 that the overall average was about (3.67) with a standard deviation of about (4.01) and the t-value was (72.96). The results of the study showed that the highest average value was for the question No. (2) at about (4.57) with a standard deviation of (0.75) with the t-value of (0.54). It indicates the scarcity of human resources concerned with overall quality management in the tourism and hotel sector. While, the average value was lower than the share of the No. (6). It is even lower than the share of the No. (6) with a value of about 3.00, a standard deviation estimated at (0.90). It indicates that there is no correct mechanism to deal with feedback when preparing marketing programs hotel in the hotel organizations in Al-Kharj.

\section{Table 9}

Statistical analysis of cultural and social constraints facing the application of overall quality management in marketing tourism services in Al-Kharj province

\begin{tabular}{|c|c|c|c|c|c|c|c|c|}
\hline \multirow[t]{2}{*}{ Groups } & \multirow[t]{2}{*}{ N. } & \multirow[t]{2}{*}{ Obstacles } & \multirow[t]{2}{*}{ Ranks } & \multirow[t]{2}{*}{ Mean } & \multirow[t]{2}{*}{ Sd. Devotion } & \multicolumn{3}{|c|}{ Test Result } \\
\hline & & & & & & $\mathrm{t}$ (value) & Sig. & Result \\
\hline \multirow[t]{7}{*}{ Culture and Social Obstacles } & 1 & $\mathrm{X} 33$ & 2 & 4.328 & 0.632 & 54.311 & $0.000 *$ & Sig \\
\hline & 2 & X34 & 1 & 4.567 & 0.754 & 54.651 & $0.000 *$ & Sig \\
\hline & 3 & $\mathrm{X} 35$ & 3 & 3.965 & 0.967 & 34.984 & $0.000 *$ & Sig \\
\hline & 4 & $\mathrm{X} 36$ & 5 & 3.221 & 0.943 & 34.141 & $0.000 *$ & Sig \\
\hline & 5 & X37 & 6 & 3.110 & 0.918 & 33.990 & $0.000 *$ & Sig \\
\hline & 6 & X38 & 7 & 3.001 & 0.898 & 33.014 & $0.000 *$ & Sig \\
\hline & 7 & X39 & 4 & 3.251 & 0.935 & 34.152 & $0.000 *$ & Sig \\
\hline \multicolumn{4}{|c|}{ General Average of Culture and Social Aspects } & & 4.001 & 72.964 & $0.000 *$ & Sig \\
\hline
\end{tabular}

* Significance in the level of 0.05

3.8 Statistical analysis of the technical constraints facing the application overall quality management in marketing tourism services in Al-Kharj province:

By examining and analyzing the specific factors of technical constraints and as described in Table 10, the overall average of the axis in general was about (3.54) with a standard deviation of about (4.00) and the values of (t) amounted to about (72.00). The highest average value of the term No. (3) was about (4.02) with standard deviation valued at about (0.62) and t-value of (53). It indicates that the hotel organizations in the province does not have up-to-date and complete databases about guests, whether from the province or outside, when preparing marketing programs directed to different segments. The lowest average value of the phrase No. (1) was estimated at (3.01) with a standard deviation of about (0.83) and the value of $(\mathrm{t})$ was about (33.21). It indicates the weakness of the electronic infrastructure of hotel organizations in al-Kharj governorate. By reviewing the results of the tests in Table 10, it is found that t-value has reached about (74.14) and is higher than its scheduled counterpart at the probability level of $1 \%$. So, we reject the hypothesis of zero, which stipulates that there are no obstacles to applying comprehensive quality management in marketing hotel services in AlKharj governorate. We accept the alternative hypothesis which indicates the obstacles to the application of the principle of overall quality management in marketing Hotel services in Al-Kharj governorate.

\section{Table 10}

Statistical analysis of the technical constraints facing the application overall quality management in marketing tourism services in Al-Kharj province

\begin{tabular}{|c|c|c|c|c|c|c|c|c|}
\hline Groups & \multirow[t]{2}{*}{ N. } & \multirow[t]{2}{*}{ Obstacles } & \multirow[t]{2}{*}{ Ranks } & \multirow[t]{2}{*}{ Mean } & \multirow[t]{2}{*}{ Sd. Devotion } & \multicolumn{3}{|c|}{ Test Result } \\
\hline & & & & & & $\mathrm{t}$ (value) & Sig. & Result \\
\hline \multirow[t]{6}{*}{ Technological Obstacles } & 1 & X40 & 6 & 3.006 & 0.832 & 33.213 & $0.000^{*}$ & Sig \\
\hline & 2 & $\mathrm{X} 41$ & 5 & 3.123 & 0.899 & 33.456 & $0.000^{*}$ & Sig \\
\hline & 3 & $\mathrm{X} 42$ & 1 & 4.021 & 0.618 & 53.021 & $0.000 *$ & Sig \\
\hline & 4 & X43 & 3 & 3.421 & 0.914 & 34.231 & $0.000^{*}$ & Sig \\
\hline & 5 & X44 & 4 & 3.210 & 0.934 & 34.334 & $0.000^{*}$ & Sig \\
\hline & 6 & $\mathrm{X} 45$ & 2 & 3.562 & 0.954 & 34.459 & $0.000^{*}$ & Sig \\
\hline \multicolumn{3}{|c|}{ General Average of Technological Aspects } & \multicolumn{2}{|c|}{3.451} & 4.000 & 71.998 & $0.000^{*}$ & Sig \\
\hline
\end{tabular}

* Significance in the level of 0.05

\section{Conclusion and Recommendations}

By reviewing the results of the statistical analysis, we have found a set of obstacles that may prevent the application of comprehensive quality management in marketing hotel products in Al-Kharj governorate. Organizational constraints for hotel organizations in the province which constitute a major obstacle i.e. poor cooperation and coordination between different departments and departments of the hotel subsidiary, lack of awareness of the importance of overall quality management, routine regulatory procedures and competitive constraints were the most important factors, seasonality of hotel work in the province, legal and legislative constraints, weak legislative structure of the hotel sector, the constraints related to the leadership aspects, comprehensive quality management system, existence of a range of cultural and social constraints and weak relationship between the community and hotel organizations, technical constraints and factors were the most important factors. In light of the results of the study, it is clear that there is an integrated system to manage the 
overall quality in the hotel organizations in Al-Kharj governorate in order to ensure the implementation of sound and correct marketing programs for these organizations. It is possible due to removing the obstacles in the way of applying comprehensive quality management in these organizations i.e. increased cooperation and coordination between the different departments and departments of hotel organizations, raising awareness of the importance of managing overall quality and updating administrative procedures and methods, modernizing the financial and administrative systems of hotel organizations, training their employees, enabling them to work and giving them full powers, study the external environment of hotel organizations in depth by finding and activating the marketing intelligence system and marketing research, updating the laws and regulations related to the tourism and hotel sector and train legal professionals on the concepts of comprehensive quality management, changing the attitudes of administrative leaders towards comprehensive quality management by promoting the spirit of teamwork and devolving powers, strengthening the relationship with society, adopting the principle of social responsibility and working to spread a culture of quality in educational and training institutions, updating the electronic infrastructure through using of software, establishing updated databases and training staff in hotel organizations and continuing scientific studies that deal with the same subject including dimensions and other analytical aspects support the current study in formulating a strategy that supports the adoption of the approach of tourism organizations to reach comprehensive quality management in their marketing of tourism services in Saudi Arabia.

\section{Acknowledgments}

The Deanship of Scientific Research at Prince Sattam Bin Abdulaziz University supported this project under the research project number \# 2019/02/10364. So, we express our gratitude to the university for this support.

\section{References}

Abdulsttar, N. (2013). TQM Requirements at Tikrit University. Arab Journal for Quality Assurance In Higher Education, $6(13), 151-166$.

Alathathi, N. (2012). Obstacles to the application of total quality management in higher education institutions in the Kingdom of Saudi Arabia. Arab Journal for Quality Assurance I Higher Education, 5(9),66 - 99.

Aldaibat, A. (2018). Obstacles to the implementation of quality management at the Jordanian private universities. Journal of ALnajah University, 32(11), 1077 - 2004.

Al-Azazi, A., \& Al-Hawamdeh, R. (2010). Measuring the perception of the quality of hotel services from the customer's perspective - An empirical study of five-star hotels in Amman. Journal of Baghdad College of Economic Sciences, 25(2), 74-88.

Alhazmi, N. (2017). Impact of total quality management on marketing of tourism services: An applied study on hotels located in Al-Kharj City in K.S.A. International Journal of Management and Economics Invention 4(1), 1595-1605.

Alhouri, M. (2012). Diagnosing the reality of applying TQM in private Jordanian hospitals . Journal of ALnajah University, $12(2), .877-911$.

Alkomaim, M. (2015). Evaluate the applicability of TQM in Yemeni government universities. Journal of ALandalus University, $12(8), 95-146$.

Alrefai, H. \& Alnajdawi, A. (2012). Determining the constraints of the application of TQM in the accounting departments of Jordanian public universities. The Second International Arab Conference on Quality Assurance in Higher Education (IACQA' 2012), 1021-1030.

Alsosi, Z. (2017). Studying the Obstacles to Applying TQM in Construction Companies. Human and Community Studies Journal, 1(2), 1-32.

Banoula, A. (2014). Relationship marketing and its impact on the quality of tourism Service. PhD Thesis, University of Algiers.

Bathath, T. (2017). Evaluating the reality of applying TQM in hotels. Journal of Human Sciences, 7(45), $1-34$.

Bazazo, A. (2010). Evaluation of the reality of the application of total quality management in hotels: a field study on a sample of five-star hotels in Jordan. Journal of Humanities, 7(45), 112 - 132.

Boubacar, K. (2009). The role of internal marketing in the development of the quality of hotel services, a field study of a sample of hotel institutions in the province of Ouargla. Master Thesis, University of Kasidi Merbah, Ouargla.

Mahmood, S., \& Ahmed, A. (2014). Relationship between TQM dimensions and organizational performance. Pakistan Journal of Commerce and Social Sciences, 8(3), 662-679.

Rady, H. (2016). Obstacles to the application of TQM in educational institutions in the gaza governorates and ways to overcome them. Arab Journal for Quality Assurance In Higher Education, 15(49), 356 - 406.

Ruqaya, S., \& Aziz, R. (2017). Requirements for total quality management as an approach to developing competitiveness of tourism service: Case study of desert tourism in Algeria. Journal of Humanities and Social Sciences, 30(1), 98-112.

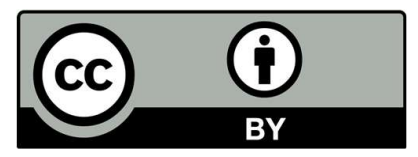

(C) 2020 by the authors; licensee Growing Science, Canada. This is an open access article distributed under the terms and conditions of the Creative Commons Attribution (CCBY) license (http://creativecommons.org/licenses/by/4.0/). 